5. Kundiyev, Yu. I., Nahorna, A. M. (2007). Profesiyne zdorov"ya v Ukrayini. Epidemiolohichnyy analiz [A professional health in Ukraine]. Kiev: Avitsena, 396.

6. Voytenko, V. P., Koshel', N. M. (2008). Invalidnist' v Ukrayini: demohrafichni studiyi [Disability in Ukraine]. Kiev: Naukovyy svit, 197.
7. Social determinants of health : the solid facts. Available at: http:www.euro.who.int/_data/assets/pdf_file

8. A review of methods used across Europe to estimate work - related accidents and illnesses among the self-employed (2010). Eur. Agency for Safety and Health at Work, 28.

Рекомендовано до публікаиії д-р мед. наук, проф. Очередько О. М. Дата надходження рукопису 25.12.2014

Крекотень Олена Миколаївна, кандидат медичних наук, доцент, кафедра соціальної медицини та організації охорони здоров'я, Вінницький національний медичний університет ім. М. I. Пирогова, вул. Пирогова, 56, м. Вінниця, Україна, 21018

E-mail: olena1977@mail.ru

Кабаненко Олена Геннадіївна, асистент, Вінницький національний медичний університет ім. М. І. Пирогова, вул. Пирогова, 56, м. Вінниця, Україна, 21018

E-mail: ya.fanwatch@yandex.ru

УДК 616.314,159.9.07

DOI: $10.15587 / 2313-8416.2015$.

\title{
ПСИХОЛОГИЧЕСКАЯ ОЦЕНКА ЭМОЦИОНАЛЬНОГО СОСТОЯНИЯ ЛИЧНОСТИ ПО ХАРАКТЕРИСТИКАМ ВЫРАЖЕНИЯ ГЛАЗ
}

\author{
(C) В. Н. Трезубов, Е. А. Булычева, Ю. В. Алпатьева, Д. С. Булычева
}

Практикуюшие стоматологи знают, как непросто найти контакт и взаимодействие с пациентами, страдаюшими заболеваниями жевательно-речевого аппарата. Наличие психохарактерологических нарушений у этих больных отмечают многие исследователи, одни из которых относят данные заболевания к разряду психосоматических, другие - к соматическим.

В связи с этим перед нами была поставлена цель: исследовать психохарактерологические особенности пациентов с патологией жевательно-речевого аппарата

Ключевые слова: психологический статус, выражение эмоций, глаза, эмоциональное состояние, жевательно-речевой аппарат

Clinical dentists know that it is very difficult to find a contact and to interact with patients suffering from diseases of the mastication and speech apparatus. Many researches pay attention to the psychiatric and character deviations of this type of patients. Some of them describe these deviations as psychosomatic, others describe them as physical.

Our goal was to explore the psychiatric and character features of the patients with the pathology of the mastication and speech apparatus and to reveal the specifics of the reduction of the disease symptoms under the influence of the adjuvant therapy. The research is based on the survey of 105 patients before and after the treatment using the "Scale of the emotional state based on the eye expression". The research revealed the changes in the emotional state of the patients with this pathology according to their eye expression. It means that the research created a new tool for the quantitative and qualitative evaluation of the eye expression as an indicator of the psycho-emotional state of a person - the tool that is additional for the basic psycho-diagnostic tests

Keywords: psychological status, expression of emotions, eyes, emotional state, mastication and speech apparatus

\section{1. Введение}

При первичном контакте с пациентом врачстоматолог внимательно оценивает его внешнюю экспрессию. Это порой происходит неосознанно, интуитивно, но всегда имеет важное значение для построения тактики поведения врача и формирования межличностного контакта с больным. Психические особенности пациентов весьма разнообразны и индивидуальны. Часть из них считываются врачом с выражения глаз, мимики и пантомимики. Для оценки глаз психологи и физиогномисты предлагают различные оценки личности по характеристикам глаз.

\section{2. Литературный обзор}

Оценкой индивидуально-психологических характеристик человека по выражению лица занимались многие ученые. Для анализа динамики выражения глаз психологами и физиогномистами предлагаются различные методики. Так, по мнению Майниной И. Н. (2011) [1], представление о личности незнакомого человека, основанное на изучении выражения его лица, включает не только «поверхностные» (черты личности), но и «глубинные» (экзистенциальные) характеристики, которые учитываются в процессе общения. 
По выражению лица можно читать многие тончайшие оттенки различных душевных волнений [2]. Следует отметить, что по глазам определяют напряженность, властность, заинтересованность, симпатию или антипатию, подчиненность и доминирование. Глаза сужаются при гневе, презрении, чувстве превосходства; расширяются при удивлении и страхе; закрываются при некоторой степени страха и стыда, покрываются «поволокой» в минуту нежности; туманятся при горе и грусти; блестят при радости и ощущении надежды. Выделяют различные оттенки взгляда: грустный, нежный, страдальческий, гневный, радостный, горестный, пугливый, самодовольный, стыдливый, удивления, уважения, презрения, силы, торжества, благоговения и другое [3-8].

Взгляд пациента оценивается в первые несколько секунд при знакомстве и формулируется его характеристика. Для оценки глаз применяют целый ряд признаков. Это - их размер, посадка, профилировка и длина глазных щелей, взгляд, фокусировка, цвет, характер строения глазниц, век, их складок и ресниц. Существенным дополнением к характеристике глаз являются брови.

Основной характеристикой известных методик, на наш взгляд, являются их громоздкость и трудоемкость. В связи с этим они не могут служить клиническими инструментами. Вследствие необходимости для клиники рабочей реальной методики нами предложена система оценки личности пациента по характеристикам выражения его глаз, которая выполняется врачом в течение двух-трех минут.

\section{3. Материалы и методы исследования}

В плане построения адекватной врачебной тактики нами было проведено психодиагностическое обследование до и после лечения 105 больных (49 мужчин и 56 женщин) в возрасте от 16 до 70 лет (средний возраст $34,9 \pm 1,3$ года).

Обследование включало в себя подробную беседу, изучение анамнеза жизни и болезни. В связи с тем, что при опросе 85 (81\%) больных указывали на наличие в анамнезе стресса (острого или хронического), 21 (20\%) жаловались на нарушение сна, 17 (16\%) на головокружение, 54 (51\%) на головные боли, 97 (92 \%) на наличие хронической усталости, 73 (69,5 \%) на раздражительность,43 (41 \%) на нарушение в сексуальной сфере, 78 (74,3\%) на пониженное настроение, а также в связи с наличием у них различных сопутствующих психосоматических заболеваний было решено провести исследование психического статуса пациентов. Поэтому проведено целенаправленное обследование больных, в том числе с использованием базовых психодиагностических опросников (Айзенка, Спилбергера-Ханина [9-12]), а также, предложенной нами, облегченной системой оценки личности по характеристикам выражения глаз. Разработанная система качественной оценки выражения глаз, характеризующая внутреннее психоэмоциональное состояние субъекта выполняется в течении 2-3 минут. Для характеристики указанного выражения применена критериально-балльная оценка. В качестве критериев использована (в возраста- ющей последовательности): «подавленность», «удрученность», «печаль», «равновесие», «приподнятость», «радость», «восторженность», то есть 7 уровней эмоционального состояния. Положительным эмоциональным критериям присваивались баллы: от +1 до +3 .

При этом балл «+3» соответствовал восторженному, эйфорическому выражению, блеску в глазах, выраженным, преимущественно радиальным, складкам вокруг них. В этом случае речь шла о восторженном эмоциональном состоянии.

Если отмечалось радостное выражение, блеск в глазах, при заметных, преимущественно радиальных, складках вокруг них, то такое состояние оценивалась баллом «+2», а психоэмоциональное состояние характеризовалось радостным фоном.

Баллом «+1» оценивалось выражение легкого довольства, при слабо выраженных, преимущественно радиальных, складках вокруг глаз, а эмоциональное состояние являлось приподнятым.

Балл «0» означал бесстрастное выражение, невыраженные или слабо выраженные морщины, складки вокруг глаз. Пациенты с таким типом выражения глаз обычно имели ровное настроение, нейтральное эмоциональное состояние.

Отрицательным критериям присваивались баллы: от -1 до -3 .

Баллом «-1» оценивали выражение легкой грусти в глазах, слабовыраженные, преимущественно горизонтальные складки, морщины вокруг них. Эмоциональное состояние пациентов при этом считалось печальным.

Подавленное выражение глаз, заметные преимущественно горизонтальные, складки вокруг них оценивались баллом «-2». Эти пациенты характеризовались удрученным эмоциональным состоянием.

Страдальческое, горестное выражение глаз, преимущественно горизонтальные выраженные складки, морщины вокруг них, оценивали баллом «-3». При этом выражении глаз пациенты находились в подавленном состоянии.

Это дает возможность, регулярно отмечая в амбулаторной карте оценку выражения глаз в баллах при посещениях стоматолога, проследить динамику эмоционального состояния пациента. Преимуществами данного способа является его простота, интерактивность, малые временные затраты, эффективность и точность.

\section{4. Результаты исследования}

Базовым психодиагностическим методом, примененным в исследовании, являлся опросник Айзенка. При исследовании пациентов по шкале «экстраверсия - интраверсия» было выявлено, что наибольшее количество лиц являлись амбивертами, т. е. представителями промежуточной между экстраи интроверсией группы. Их число до лечения составило - 31 человек или 29,52 \% от всей группы обследуемых. После лечения эта цифра выросла до 36 человек $(34,3$ \%). На момент первичного обследования, до лечения, у 27 больных (25,7 \%) имелась тенденция к интроверсии. После лечения их число уменьшилось 
до 21 человека (20,0 \%). Согласно результатам исследования до и после лечения интровертами были соответственно $25(23,81 \%)$ и $23(21,90 \%)$.

Представители экстраверсии и лица с тенденцией к экстраверсии составляли до лечения одинаковое количество - по 11 человек (10,48 \%). После лечения число экстравертов осталось прежним - 11 пациентов $(10,48 \%)$, а 14 больным (13,33 \%) стала свойственна тенденция к экстраверсии.

Здесь необходимо сделать уточнение. Дело в том, что после лечения по данным психодиагностического опросника наблюдалось «превращение» некоторых интровертов в экстраверты или амбиверты. Такая метаморфоза нелогична, так как интроверсия, экстраверсия и амбиверсия - базовые психологические генетически обусловленные характеристики индивидуума. Объяснить это изменение можно, с одной стороны субъективизмом ответов больных, а с другой влиянием технологических и методических ограничений опросника.

Данные результатов обследования по шкале «эмоциональная лабильность - стабильность» показали, что до лечения тенденция к эмоциональной стабильности наблюдалась у 21 человека (20\%), а сама стабильность у 18 больных $(17,1 \%)$. После лечения, число лиц с тенденцией к стабильности несколько выросло, достигнув 26 (24,7 \%), а с абсолютной стабильностью достигло уровня $23(21,9 \%)$.

Кроме того, применены обе шкалы (личностной и реактивной тревожности) методики Спилбергера-Ханина.

Высокий уровень личностной тревожности до лечения наблюдался у 46 человек (43,8 \%), средний у 41 больного (39\%) и лишь у 17 пациентов (16,2\%) он был низкий. После лечения высокий уровень личностной тревожности сохранился у 40 больных $(38,1 \%)$, средний остался на прежнем уровне 42 человек (40\%) и низкий определен у 23 (21,9\%) вместо 17 человек до лечения.

По данным результатов обследования не установлено достоверного уменьшения уровня личностной тревожности с $(40,7 \pm 2,5)$ баллов до лечения, до $(36,3 \pm 2,9)$ баллов после лечения $(\mathrm{t}=1,1 ; \mathrm{p}>0,05)$, что вполне естественно и ожидалось нами. Вероятно, отсутствие статистически достоверного снижения обусловлено тем, что личностная тревожность является относительно устойчивой, во много конституционально обусловленной индивидуальной характеристикой.

Результаты обследования больных по шкале реактивной тревожности показали следующее: высокий уровень реактивной тревожности (наблюдался у 60 (57,1\%), обследуемых данной группы, средний - у 31 больных $(29,5 \%)$, низкий - у 14 пациентов (13,3\%).

После лечения высокий уровень реактивной тревожности сохранился у 33 больных (31,4\%), средний стал у 45 пациентов $(42,8 \%)$ и низкий зарегистрирован у 27 человек $(25,7 \%)$.

Тенденция к уменьшению имела место, но ее не удалось подтвердить до $(44,5 \pm 4,1$ баллов) и после
$(36,3 \pm 3,2$ баллов) лечения $(\mathrm{t}=1,6 ; \mathrm{p}>0,05)$, но по количеству больных уменьшение заметно.

При использовании «Шкалы внутреннего эмоционального состояния по выражению глаз» пациенты тестированы по всем семи уровням входящих в данную методику: подавленность, удрученность, печаль, равновесие, приподнятость, радость, восторженность. Результаты исследования достоверно установили изменения показателей по шкале внутреннего эмоционального состояния по выражению глаз: от $3,6 \pm 0,56$ баллов перед лечением, до 5,3 $\pm 0,41$ баллов после лечения $(\mathrm{t}=2,44$; $\mathrm{p}<0,05)$. Как следует из диаграммы на момент первичного обследования внутреннее эмоциональное подавленное состояние по выражению глаз наблюдалось у 15 человек (14,3\%), удрученное - у 23 больных (21,9 \%), а печальное - у 21 пациента (20\%). После лечения число больных с подавленным выражением глаз значительно уменьшилось - до 4 пациентов (3,8 \%), с удрученным - снизилось до 8 исследуемых (7,6 \%), а с печальным - до 6 человек (5,7 \%). Больные с нейтральным ровным (внутренним) эмоциональным состоянием по выражению глаз составили одинаковое количество как до, так и после лечения - по 30 человек (28,6 \%). До лечения приподнятое внутреннее эмоциональное состояние по выражению глаз наблюдалось у 8 пациентов (7,6 \%), радостное - лишь у 3 больных $(2,86 \%)$, а востор-женное - только у 5 человек $(4,76 \%)$. После лечения, число больных с приподнятым эмоциональным состоянием по выражению глаз значительно возросло - до 19 человек (18 \%), с радостным - увеличилось до 22 исследуемых 20,9\%), а с восторженным изменилось до 16 пациентов (15\%).

\section{5. Выводы}

Таким образом, наряду с улучшением динамики психоэмоционального состояния, подтверждаемого клиническим и параклиническим обследованием, параллельно изменялось выражение глаз пациентов. Это указывает на точность и валидность предлагаемой системы оценки эмоциональной окраски выражения глаз обследуемых.

Итак, можно утверждать, что нами создан инструмент для количественно-качественной оценки выражения глаз, как показателя внутреннего психоэмоционального состояния человека, который является дополнительным несложным, но информативным диагностическим средством, способствующим уточнению экспертизы психоэмоционального статуса пациента.

\section{Литература}

1. Майнина, И. Н. Оценка "глубинных" индивидуально-психологических характеристик человека по выражению его лица [Текст] : дис. ... канд. психол. наук: 19.00.01 / И. Н. Майнина. - М., 2011. - 152 с.

2. Чуфаровский, Ю. В. Оценка личности по внешним признакам [Текст] / Ю. В. Чуфаровский. «Элитариум», центр дистанционного образования. СПб, 2007.

3. Артёмцева, Н. Г. Восприятие психологических характеристик человека по его «разделенному» лицу [Текст] : дис. ... канд. психол. наук: 19.00.04 / Н. Г. Артёмцева. - ИПРАН, 2003. - 170 с. 
4. Барабанщиков, В. А. Восприятие индивидуальнопсихологических особенностей человека в ситуациях непосредственного и викарного общения [Текст] / В. А. Барабанщиков, А. А. Демидов // Вестник МГОУ. - 2007. № 3. - C. 17-28.

5. Барабанщиков, В. А., Демидов А.А. Оценка индивидуально-психологических особенностей человека по выражению его лица [Текст] : матер. 7-й Всер. науч.-прак. конф. / В. А. Барабанщиков, А. А. Демидов // Дружининские чтения. - Сочи, 2008. -135 с.

6. Барабанщиков, В. А. Доверие к человеку при первичном восприятии его лица [Текст] / В. А. Барабанщиков, Л. А. Хрисанфова. - Методы исследования психологических структур и их динамики. М.: ИП РАН, 2007.C. $117-127$.

7. Дивеев, Д. А. Роль формы лица в восприятии индивидуально - психологических характеристик человека [Текст] : дис. ... канд. псих. наук: 19.00.01 / Д. А. Дивеев. M., 2009. - 144 c.

8. Лабунская, В. А. Экспрессия человека: общение и межличностное познание [Текст] / В. А. Лабунская. - СПб.: Питер, 2001. - 544 с.

9. Айзенк, Г. Ю. Оценка эмоций: психологические параметры и методы. Эмоции, их параметры и оценка [Текст] / Г. Ю. Айзенк. - Ред. Л. Леви, Нью-Йорк, 1975. C. $439-468$.

10. Ханин, Ю. Л. Краткое руководство по применению Шкалы реактивной и личностной тревожности Ч. Д. Спилбергера [Текст] / Ю. Л. Ханин. - Л.: ЛНИИФК, 1976. $-16 \mathrm{c}$.

11. Булычева, Е. А. Дифференцированный подход к разработке патогенетической терапии больных с дисфункцией височно-нижнечелюстного сустава, осложненной гипертонией жевательных мышц [Текст] : дис. .... докт. мед. наук: 14.01.14,19.00.04 / Е. А. Булычева. - СПбГМУ. СПб, 2010. - 396 с.

12. Трезубов, В. Н. Исследование особенностей личности пациентов с расстройствами височно - нижнечелюстного сустава (ВНЧС), осложненными парафункциями жевательных мышц [Текст] / В. Н. Трезубов, Б. Д. Карвасарский, Е. А. Булычева, Е. А. Колотильщикова, Е. И. Чехлатый // Институт Стоматологии.- 2006. № $31 .-$ C. 33-35

\section{References}

1. Maynina, I. N. (2011). The evaluation of the inner individual psychological characteristics of the person by their expression. Moscow, 152.

2. Chufarovcky, Y. V. (2007). The evaluation of the personality by external signs. "Elitarium" Distance Learning Center. St. Petersburg.

3. Artyomtseva, N. G. (2003). The perception of the psychological characteristics of a person by "separation" face. IPRAN, 170

4. Barabanshikov, V. A., Demidov, A. A. (2007). Perception of individual psychological characteristics of a person in situations of direct and vicarious communication. Bulletin of MGOU, 3, 17-28.

5. Barabanshikov, V. A., Demidov, A. A. (2008). Evaluation of individual psychological characteristics of a person by his expression. Druzhininskye tchteniya: Proceedings of the 7th Russian Applied Science Conf., Sochi.

6. Barabanshikov, V. A., Khrisanfova, L. A. (2007). The credibility of the person by the first perception of his face. Methods of psychological structures and their dynamics. Moscow: IP RAS, 117-127.

7. Diveev, D. A. (2009). The role of the shape of the face in the perception of the individual psychological characteristics of a person. Moscow, 144.

8. Labunskaya, V. A. (2001). Expression of the human: communication and interpersonal knowledge. SPb: Peter, 544.

9. Eysenck, H. J. (1975). The evaluation of emotions: psychological parameters and methods. Emotions, their parameters and evaluation. L. Levy, New York, 439-468.

10. Hanin, Y. L. (1976). Quick Guide to the application of the scale of reactive and personal anxiety by Charles D. Spielberger. Leningrad: LNIIFK, 16.

11. Bulycheva, E. A. (2010). The differentiated approach to the development of the pathogenetic therapy of patients with dysfunction of the temporomandibular joint, with masticatory muscles hypertension complications. State Medical University. St. Petersburg, 396.

12. Trezubov, V. N., Karvasarsky, B. D., Bulycheva, E. A., Kolotilschikova, E. A., Chekhlaty, E. I. (2006). The study of the personality of patients with temporomandibular joint disorders (TMJ), with parafunctions of the masticatory muscles complication. Institute of Stomatology, 31, 33-35.

Трезубов Владимир Николаевич, доктор медицинских наук, профессор, заслуженный деятель науки РФ, кафедра ортопедической стоматологии и материаловедения с курсом ортодонтии, Первый Санкт-Петербургский государственный медицинский университет им. И. П. Павлова, ул. Л. Толстого, 6/8, г. Санкт-Петербург, Россия, 197022

E-mail: trezubovvn@mail.ru

Булычева Елена Анатольевна, доктор медицинских наук, профессор, MSc, кафедра ортопедической стоматологии и материаловедения с курсом ортодонтии, Первый Санкт-Петербургский государственный медицинский университет им. И. П. Павлова, ул. Л. Толстого, 6/8, г. Санкт-Петербург, Россия, 197022 E-mail: elenapositive @rambler.ru

Алпатьева Юлия Викторовна, аспирант, кафедра ортопедической стоматологии и материаловедения с курсом ортодонтии, Первый Санкт-Петербургский государственный медицинский университет им. И. П. Павлова, ул. Л. Толстого, 6/8, г. Санкт-Петербург, Россия, 197022

E-mail: alpateva1981@mail.ru

Булычева Дарья Сергеевна, Первый Санкт-Петербургский государственный медицинский университет им. И. П. Павлова, ул. Л. Толстого, 6/8, г. Санкт-Петербург, Россия, 197022

E-mail: missbulychevadaria@yandex.ru 